See Article page 2070.

\section{Commentary: Setting priorities in coronary artery bypass grafting: Do what you can when you can-as long as it's arterial}

\author{
Shuab Omer, MD, ${ }^{\mathrm{a}}$ and Faisal G. Bakaeen, $\mathrm{MD}^{\mathrm{b}}$
}

Lack of durable conduits and incomplete revascularization (IR) have been implicated as culprits for decreased survival after coronary revascularization. In this issue of the Journal, Rosenblum and colleagues ${ }^{1}$ have demonstrated that multiarterial coronary artery bypass grafting (CABG) provides a modest mid-term survival benefit over single arterial $\mathrm{CABG}$, irrespective of completeness of coronary revascularization (CR). The practical message is that when $\mathrm{CR}$ is not possible, surgeons should strongly consider multiple arterial conduits to mitigate the adverse outcomes associated with IR. But things are not that simple in the CABG world.

Despite the consensus about the superiority of CR over IR, there are some salient points that need to be emphasized. (1) There is a lack of consensus regarding CR, which itself is variably and arbitrarily defined across studies. (2) The optimal extent of myocardial revascularization in patients with coronary artery disease (CAD) is controversial and lacks uniformity. (3) CABG studies generally fail to provide data on viability and functional significance of bypassed territories.

The Fractional Flow Reserve vs Angiography for Multivessel Evaluation (FAME) ${ }^{2}$ trial showed a clear benefit of fractional flow reserve (FFR)-guided percutaneous revascularization strategy for multivessel CAD. In addition, nonfunctional residual angiographic lesions seem not to

\footnotetext{
From the ${ }^{\mathrm{a}}$ Department of Advanced Cardiopulmonary Therapies and Transplantation, The University of Texas Health Science Center at Houston, McGovern Medical School, Houston, Tex; and ${ }^{\mathrm{b}}$ Department of Thoracic and Cardiovascular Surgery, Heart and Vascular Institute, Cleveland Clinic, Cleveland, Ohio.

Disclosures: Authors have nothing to disclose with regard to commercial support.

Received for publication Nov 27, 2019; revisions received Nov 27, 2019; accepted for publication Nov 28, 2019; available ahead of print Dec 14, 2019.

Address for reprints: Shuab Omer, MD, Department of Advanced Cardiopulmonary Therapies and Transplantation, The University of Texas Health Science Center at Houston, McGovern Medical School, Houston, TX 77030 (E-mail: shuab.omer@ uth.thc.edu).

J Thorac Cardiovasc Surg 2021;161:2081-2

$0022-5223 / \$ 36.00$

Copyright (C) 2019 by The American Association for Thoracic Surgery

https://doi.org/10.1016/j.jtcvs.2019.11.111
}

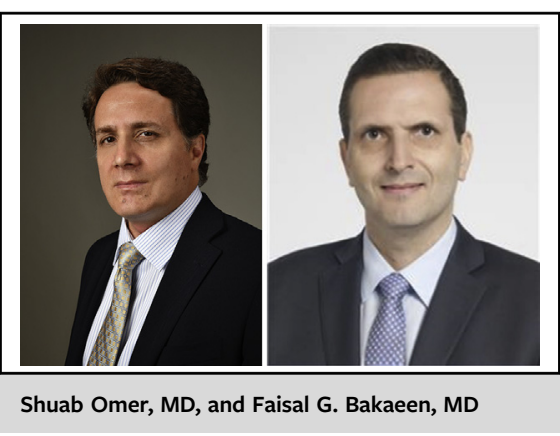

CENTRAL MESSAGE

When complete coronary revascularization is not possible, surgeons should strongly consider multiple arterial conduits to mitigate the adverse outcomes associated with incomplete coronary revascularization.

predict worse outcomes based on SYNTAX score, supporting the functional $\mathrm{CR}$ concept rather than angiographic $\mathrm{CR}$ alone. ${ }^{3}$ Importantly, there is discrepancy in more than a third of the cases between the angiographic and FFR designation of the hemodynamic significance of the coronary lesions. ${ }^{3,4}$ The impact of FFR-guided revascularization and functional completeness of revascularization remains largely unknown for surgical revascularization. The measure of completeness of revascularization in the study by Rosenblum and colleagues ${ }^{1}$ was based entirely on crude angiographic data with no adjustments for myocardium at risk.

But why did an experienced team of surgeons at a major CABG center leave $36 \%$ of their patients incompletely revascularized? We have no information relating to the actual reasons; however, the rate may be exaggerated due to the loose CR criteria adopted by the authors. Interestingly, in a study by Rastan and colleagues, ${ }^{5}$ the most common reasons for IR in CABG include small vessel diameter $(63 \%$ of cases), severely calcified vessels (25\%), and myocardial scarring (4\%). Therefore, it's likely that the vast majority of cases that are incompletely revascularized are not due to technical ineptitude of the surgeon or by choice, but a reality dictated by diffuse and complex CAD, which is by itself a negative prognostic marker.

With regards to the use of arterial conduits, the recently published 10-year follow-up of the Arterial Revascularization Trial (ART) trial ${ }^{6}$ failed to show any survival benefit of 
bilateral internal mammary grafting over single mammary grafting but did show a survival advantage in the astreated analysis comparing multiarterial versus single arterial grafting. The risk of bias cannot be ignored in the as-treated analysis of the ART trial and likewise for the propensity matching in the study at hand and, thus, these results should be interpreted with caution.

In summary, the findings of Rosenblum and colleagues ${ }^{1}$ are plausible regarding the advantages of multiarterial grafting, but, hypothesis-generating at best, relating to the suggestion that multiarterial grafting can totally counter incomplete revascularization. It is reasonable to infer that surgeons often have little control over the goal of achieving CR, which is typically governed by the extent of the coronary disease and quality of target vessels. Finally, when appropriate and in the hands of experts, choosing arterial grafts can enhance patient longevity and should be a priority.

\section{References}

1. Rosenblum JM, Binongo J, Wei J, Liu Y, Leshnower BG, Chen EP, et al. Priorities in CABG: is mid-term survival more dependent on completeness of revascularization or multiple arterial grafts? J Thorac Cardiovasc Surg. 2021; 161:2070-8.e6

2. Tonino PA, De Bruyne B, Pijls NH, Siebert U, Ikeno F, van't Veer M, et al. Fractional flow reserve versus angiography for guiding percutaneous coronary intervention. $N$ Engl J Med. 2009;360:213-24.

3. De Bruyne B, Pijls NH, Kalesan B, Barbato E, Tonino PA, Piroth Z, et al. Fractional flow reserve guided PCI versus medical therapy in stable coronary disease. N Engl J Med. 2012;367:991-1001.

4. Kobayashi Y, Nam CW, Tonino PA, Kimura T, De Bruyne B, Pijls NH, et al. The prognostic value of residual coronary stenoses after functionally complete revascularization. J Am Coll Cardiol. 2016;67:1701-11.

5. Rastan AJ, Walther T, Falk V, Kempfert J, Merk D, Lehmann S, et al. Does reasonable incomplete surgical revascularization affect early or long-term survival in patients with multivessel coronary artery disease receiving left internal mammary artery bypass to left anterior descending artery? Circulation. 2009; 120:S70-7.

6. Taggart DP, Benedetto U, Gerry S, Lees B, Gerry S, Benedetto U, et al. Bilateral versus single internal-thoracic-artery grafts at 10 years. N Engl J Med. 2019;380: $437-46$. 